\title{
Low triiodothyronine and exercise capacity in heart failure
}

\author{
Marianna Fontana a , Claudio Passino a,c,*, Roberta Poletti ${ }^{a}$, Luc Zyw ${ }^{\text {a }}$, Concetta Prontera ${ }^{\text {b }}$ \\ Maria Scarlattini $^{\mathrm{b}}$, Aldo Clerico ${ }^{\mathrm{b}, \mathrm{c}}$, Michele Emdin $^{\mathrm{a}}$, Giorgio Iervasi ${ }^{\mathrm{d}}$ \\ a Division of Cardiovascular Medicine, Fondazione G. Monasterio CNR-Regione Toscana, Pisa, Italy \\ ${ }^{\mathrm{b}}$ Laboratory of Cardiovascular Endocrinology, Fondazione G. Monasterio CNR-Regione Toscana, Pisa, Italy \\ c Scuola Superiore Sant'Anna, Pisa, Italy \\ d CNR Institute of Clinical Physiology, Pisa, Italy
}

\section{A R T I C L E I N F O}

Article history:

Received 26 August 2009

Received in revised form 30 July 2010

Accepted 5 September 2010

Available online 2 October 2010

\section{Keywords:}

Heart failure

Cardiopulmonary test

Thyroid

Peak oxygen consumption

\begin{abstract}
A B S T R A C T
Background: Cardiopulmonary exercise test (CPT) has a prominent value in assessing clinical severity in chronic heart failure (HF) patients. Reduced free triiodothyronine (fT3) plasma level is associated with a more severe disease and prognosis. The aim of this study was to evaluate the relationship between low fT3 plasma level and reduced exercise capacity in chronic HF, and to determine the influence of a low T3 status in subsets of patients with different functional impairment.

Methods and results: $240 \mathrm{HF}$ patients (79\% males; age $62 \pm 12$ years, mean \pm standard deviation; left ventricular ejection fraction, $\mathrm{EF}, 30 \pm 9 \%$ ) underwent a CPT, clinical and neurohormonal characterization (assay for plasma brain natriuretic peptide, BNP, norepinephrine, aldosterone, renin activity, fT3, free T4, thyroid-stimulating hormone). At multivariate analysis in the whole population, age, gender and BNP level were independently associated with peak VO2, whereas in patients with severe functional impairment (peak $\mathrm{VO} 2<14 \mathrm{ml} / \mathrm{min} / \mathrm{kg}$ ) fT3 resulted independently related to peak VO2, together with gender and BNP. When patients with peak VO2 $<14 \mathrm{ml} / \mathrm{min} / \mathrm{kg}$ were divided according to fT3 levels, patients with low T3 syndrome showed reduced exercise capacity and worse ventilatory efficiency.

Conclusions: BNP and fT3 are independently associated with exercise capacity in severely compromised HF patients.
\end{abstract}

(C) 2010 Elsevier Ireland Ltd. All rights reserved.

\section{Introduction}

Exercise intolerance is a hallmark of heart failure [1]. Cardiopulmonary exercise testing (CPT) has been widely used in the assessment of heart failure (HF), allowing an objective assessment of exercise capacity, ventilatory response, clinical severity, and prognosis [1-3]. During exercise, oxygen uptake (VO2) directly correlates with cardiac output. An inadequate cardiac output reserve is the primary determinant of the impairment in aerobic capacity in asymptomatic or mildly symptomatic HF patients [4]. However, when HF worsens, several neurohormonal systems are activated, with a predominance of sympathetic, renin-angiotensin-aldosterone systems [5], causing downregulation/desensitization of beta-adrenergic receptors and determining a decreased skeletal muscle vasodilation in response to exercise: these mechanisms appear to be critical determinants of decreased peak VO2 in moderate to severe HF [6].

As part of this complex neurohormonal response to cardiac dysfunction, an altered thyroid hormone metabolism, i.e. the "low

\footnotetext{
* Corresponding author. Division of Cardiovascular Medicine, Fondazione G. Monasterio, Via Giuseppe Moruzzi 1, 56124 Pisa, Italy. Tel.: +39 050 3152191; fax: +39050 3152109 .

E-mail address: passino@ifc.cnr.it (C. Passino).
}

triiodothyronine (T3) syndrome", has been reported in approximately $30 \%$ of patients with advanced HF and its presence is an independent predictor of death [7-11]. This is characterized by low circulating levels of the biologically active form of $\mathrm{T} 3$, in the presence of a normal level of thyrotropin (thyroid-stimulating hormone [TSH]) and of the pro-hormone thyroxin (T4), associated with abnormal peripheral conversion of T4 to T3 [12,13].

The pathophysiological role of progressive decrease of T3 in HF has not yet been completely established [14], but the cardiovascular system is a principal target of the thyroid hormone, acting on heart function and trophism, vascular tone [15-17] as well as on the skeletal muscle system [18].

The possible role of the altered thyroid profile on reduced functional capacity in HF patients, as assessed by CPT, was examined in only one previous study that reported a positive correlation between total T3 levels and peak VO2 [19]. However, the number of patients examined was small and neither free fractions of thyroid hormones nor the other neurohormonal axes were considered.

The aim of this study was to evaluate the relationship between free T3 (fT3) and reduced exercise capacity in a larger HF population, who underwent a comprehensive clinical and neurohormonal evaluation. Moreover, we aimed to determine the influence of low T3 status in subsets of patients with different functional impairment (dividing 
Table 1

Patient characteristics.

\begin{tabular}{|c|c|c|c|}
\hline Variable & $\begin{array}{l}\text { All patients } \\
(n=240)\end{array}$ & $\begin{array}{l}\text { Peak VO2>14 } \\
(n=84)\end{array}$ & $\begin{array}{l}\text { Peak VO2 }<14 \\
(n=156)\end{array}$ \\
\hline Age, years & $62 \pm 12$ & $54 \pm 13$ & $66 \pm 10^{*}$ \\
\hline Gender, $\mathrm{M} / \mathrm{F}, n$ & $190 / 50$ & $78 / 6$ & $112 / 44^{*}$ \\
\hline Body mass index, $\mathrm{kg} / \mathrm{m}^{2}$ & $27 \pm 4$ & $26 \pm 8$ & $27 \pm 5$ \\
\hline Hypertension, $n(\%)$ & $112(47)$ & $38(45)$ & $73(48)$ \\
\hline Diabetes, $n(\%)$ & $74(31)$ & $12(14)$ & $61(39)^{*}$ \\
\hline Dyslipidemia, $n(\%)$ & $89(37)$ & $35(42)$ & $53(35)$ \\
\hline Ischaemic etiology, $n(\%)$ & 97 (49) & $26(31)$ & $70(45)^{*}$ \\
\hline $\mathrm{EF}, \%$ & $30 \pm 9$ & $35 \pm 9$ & $31 \pm 8^{*}$ \\
\hline LVEDD, mm & $62.4 \pm 7.6$ & $62 \pm 8$ & $63 \pm 7$ \\
\hline LVEDV, mL & $225 \pm 73$ & $211 \pm 80$ & $231 \pm 70$ \\
\hline NYHA class (I/II/III), $n$ & $37 / 125 / 78$ & $38 / 46 / 0$ & $8 / 91 / 57^{*}$ \\
\hline $\mathrm{ECrCl}, \mathrm{ml} / \mathrm{min}$ & $82 \pm 32$ & $93 \pm 25$ & $76 \pm 34^{*}$ \\
\hline $\mathrm{TSH}, \mu \mathrm{IU} / \mathrm{mL}$ & $\begin{array}{l}1.54 \\
(0.98-2.45)\end{array}$ & $\begin{array}{l}1.41 \\
(0.94-2.23)\end{array}$ & $\begin{array}{l}1.69 \\
(0.98-2.50)\end{array}$ \\
\hline fT3, ng/L & $2.43 \pm 0.42$ & $2.56 \pm 0.40$ & $2.3 \pm 0.41^{*}$ \\
\hline $\mathrm{fT} 4, \mathrm{ng} / \mathrm{L}$ & $12.22 \pm 2.84$ & $11.71 \pm 2.67$ & $12.4 \pm 2.91^{*}$ \\
\hline Norepinephrine, ng/L & $531(352-737)$ & $\begin{array}{l}427 \\
(277-588)\end{array}$ & $\begin{array}{l}600 \\
(418-805)^{*}\end{array}$ \\
\hline $\begin{array}{l}\text { Plasma renin activity, } \\
\text { ng/L/h }\end{array}$ & $1.58(0.45-4.6)$ & $\begin{array}{l}1.17 \\
(0.53-2.58)\end{array}$ & $\begin{array}{l}1.69 \\
(0.36-5.16)\end{array}$ \\
\hline Aldosterone, ng/L & $140(88-207)$ & $132(86-205)$ & $145(89-226)$ \\
\hline $\mathrm{BNP}, \mathrm{ng} / \mathrm{L}$ & $147(43-348)$ & $46(23-145)$ & $229(86-516)^{*}$ \\
\hline \multicolumn{4}{|l|}{ Medications } \\
\hline Furosemide, $n(\%)$ & $194(80)$ & $57(68)$ & $137(89)^{*}$ \\
\hline Beta-blocker, $n(\%)$ & $202(84)$ & $75(89)$ & $113(72)$ \\
\hline ACEi/ARBs, $n(\%)$ & $207(86)$ & $82(98)$ & $125(80)$ \\
\hline Spironolactone, $n(\%)$ & $144(60)$ & $19(22)$ & $125(80)^{*}$ \\
\hline $\begin{array}{l}\text { Device therapy (ICD/CRT), } \\
n(\%)\end{array}$ & $29(12) / 38(16)$ & $6(7) / 8(10)$ & $23(15) / 30(19)$ \\
\hline
\end{tabular}

Values are expressed as mean \pm standard deviation for normally distributed variables, and as median (25th-75th percentile) for non-normally distributed variables; percentage and number of cases are presented for binary variables. Diabetes, hypertension and dyslipidemia were considered positive if a patient had a documented history or was currently on antidiabetic, antihyertensive or lipidlowering drug treatment, respectively.

$\mathrm{AF}=$ Atrial fibrillation; $\mathrm{EF}=$ left ventricular ejection fraction; $\mathrm{LVEDD}=$ left ventricular enddiastolic diameter; LVEDV = left ventricular end diastolic volume; NYHA in $=$ New York Heart Association functional class; $\mathrm{ECrCl}=$ estimated creatinine clearance by Cockroft-Gault formula; TSH = thyroid stimulating hormone; fT3=free triiodothyronine; fT4 = free thyroxine; $\mathrm{BNP}=$ brain natriuretic peptide; $\mathrm{ACE}=$ angiotensinogen converting enzyme inhibitors; ARBs $=$ angiotensin receptor blockers

* $p<0.05$ vs patients with peak $\mathrm{VO} 2>14$.

patients according to the peak VO2 achieved), owing to the different determinants of exercise intolerance, in asymptomatic/mildly symptomatic patients (i.e. a reduced cardiac output reserve) and in moderate/severe chronic HF patients (where abnormal "peripheral" mechanisms play a greater role).

\section{Methods}

From January 2005 and December 2007 we evaluated 407 consecutive patients with systolic HF ( $<50 \%$ left ventricular ejection fraction, EF; New York Heart Association, NYHA, functional classifications I-III), referred to our Cardiovascular Medicine Division for HF management. Of the 407 patients 4 were excluded because of overt primary hypothyroidism [20] (TSH $>10 \mathrm{mIU} / \mathrm{mL}$ and free T4, fT4 $<7 \mathrm{ng} / \mathrm{L}$ ), 5 patients because of hyperthyroidism [21] (free T3, fT3 $>4.2 \mathrm{ng} / \mathrm{L}$ and fT4 $>18.5 \mathrm{ng} / \mathrm{L}$ with undetectable TSH level); 57 patients were excluded because of concomitant treatment with amiodarone, LT4 or T3 $(n=57), 7$ patients because of advanced renal impairment (i.e. estimated creatinine clearance, $\mathrm{ECrCl}<25 \mathrm{ml} / \mathrm{min}$, estimated by the Cockroft-Gault formula), 3 patients for severe pulmonary or systemic disease and 91 patients were not able to perform a valid CPT. Ultimately, 240 patients were enrolled.

All patients underwent a clinical, humoral and echocardiographic evaluation, according to the recommendations of the American Society of Echocardiography [22], CPT, thyroid function profile and assay of plasma BNP, catecholamines, renin activity (PRA) and aldosterone as described elsewhere [23,24]. All patients were on stable, optimal pharmacological and device treatment.

The study was approved by the institutional Ethics Review Committee, and conformed to the principles outlined in the Declaration of Helsinki; all patients gave their informed consent.

\subsection{Neurohormonal and thyroid evaluation}

Blood samples were withdrawn from an antecubital vein after a 20 -min period of supine rest between 8 and 9 a.m., after overnight fasting. The methods employed for the assay of plasma BNP, catecholamines, renin activity (PRA) and aldosterone are described elsewhere [23,24]. During the same morning fT3, fT4, and TSH were all measured by a completely automated AIA 600 system (Tosho Corporation). The reference intervals for our laboratory were as follows: fT3, 2.1 to $4.2 \mathrm{ng} / \mathrm{L}$ (i.e. 3.2 to $6.5 \mathrm{pmol} / \mathrm{L}$ ); fT4, 7.1 to $18.5 \mathrm{pg} / \mathrm{ml}$ (i.e. 9.2 to $24 \mathrm{pmol} / \mathrm{L}$ ); and TSH, 0.3 to $3.8 \mathrm{mIU} / \mathrm{L}$.

\subsection{Cardiopulmonary exercise testing}

A CPT was performed by exercise on a bicycle ergometer using a step protocol with increments of $10 \mathrm{~W} / \mathrm{min}$. We measured $\mathrm{VO2}, \mathrm{CO} 2$ production, and minute ventilation by means of breath-to-breath gas analysis (Vmax, Sensormedics, Conshohocken, Pennsylvania). Peak oxygen consumption (peak VO2) (the highest value at endexercise, as 20-s average) and ventilatory efficiency on exercise (slope of the ventilation vs VCO2 relation in its linear part) were determined. We then chose the peak VO2 cut-off of $14 \mathrm{ml} / \mathrm{min} / \mathrm{kg}$, whose prognostic value is well established [25], to test the influence of several pathophysiological markers on exercise capacity at different stages of functional impairment.

\subsection{Statistical analysis}

Statistical analysis was performed using SPSS version 13.0. Data is expressed as mean \pm standard deviation for variables with Gaussian distribution and as median, 25th-75th percentile for variables with log-normal distribution. Groups were compared for categorical data or frequency of events using the chi-squared test and for continuous variables using the Student's $t$ test or the Mann-Whitney $U$ test, as appropriate (all tests were 2-sided). Log-transformed values of original data were used in parametric and regression statistical analyses for continuous variables (such as BNP), known to share a log-normal distribution.

Linear regression analysis was performed to assess the relationship between indices of exercise capacity and other variables. A multiple linear regression model, which included all variables found to be statistically significant at univariate linear regression $(P<0.05)$, was also used to tease out the relationship between the different parameters and exercise capacity.

The diagnostic accuracy of BNP and fT3 in identifying patients with peak VO2 below $14 \mathrm{ml} / \mathrm{min} / \mathrm{kg}$ was quantified in terms of area under the ROC (Receiver Operating Characteristic) curves (AUC). ROC curve analysis provided optimum cut-off values of BNP and $\mathrm{fT} 3$ concentration (at the point of ROC curve corresponding to maximal sum of specificity and sensitivity), as well as corresponding sensitivity and specificity.

\section{Results}

Clinical, humoral, and echocardiographic parameters as well as level of neurohormones, thyroid hormones and TSH are summarized in Table 1. CPT findings are summarized in Table 2.

Table 2

Cardiopulmonary test findings.

\begin{tabular}{lccc}
\hline Variable & $\begin{array}{c}\text { All patients } \\
(n=240)\end{array}$ & $\begin{array}{l}\text { Peak VO2 }>14 \\
(n=84)\end{array}$ & $\begin{array}{c}\text { Peak VO2 }<14 \\
(n=156)\end{array}$ \\
\hline Rest HR & $72 \pm 13$ & $71 \pm 16$ & $73 \pm 12$ \\
Rest BP & $107 \pm 20$ & $110 \pm 23$ & $105 \pm 21$ \\
Rest VO2, ml/min/kg & $2.44 \pm 0.94$ & $2.56 \pm 1.04$ & $2.38 \pm 0.89$ \\
Rest VO2, L/min & $0.19 \pm 0.7$ & $0.20 \pm 0.06$ & $0.18 \pm 0.08^{*}$ \\
Peak HR, bpm & $121 \pm 25$ & $134 \pm 20$ & $113 \pm 26^{*}$ \\
Peak SBP, mmHg & $158 \pm 28$ & $170 \pm 25$ & $151 \pm 27^{*}$ \\
Peak VO2, L/min & $0.97 \pm 0.40$ & $1.37 \pm 0.34$ & $0.74 \pm 0.23^{*}$ \\
Peak VO2, ml/min/kg & $12.5 \pm 4.5$ & $17.4 \pm 3.2$ & $9.86 \pm 2.37^{*}$ \\
Peak VO2,\% predicted & $45 \pm 15$ & $58 \pm 13$ & $38 \pm 10^{*}$ \\
Peak oxygen pulse, mL/beat & $8.0 \pm 3.0$ & $10.4 \pm 2.8$ & $6.7 \pm 2.2^{*}$ \\
Circulatory power, & $2028 \pm 925$ & $2985 \pm 755$ & $1508 \pm 492^{*}$ \\
$\quad$ mmHg ml/min/kg & & & \\
Peak work rate, W & $70 \pm 35$ & $114 \pm 29$ & $63 \pm 21^{*}$ \\
BWi work rate, W/kg & $1.04 \pm 0.39$ & $1.43 \pm 0.31$ & $0.84 \pm 0.24^{*}$ \\
Peak RPP, bpm mmHg & $19,000 \pm 5700$ & $22,880 \pm 5007$ & $17,166 \pm 5085$ \\
VE/VCO2 slope & $37 \pm 10$ & $32 \pm 8$ & $40 \pm 10^{*}$ \\
Peak RER & $1.1 \pm 0.1$ & $1.13 \pm 0.09$ & $1.07 \pm 0.13^{*}$ \\
\hline
\end{tabular}

Values are expressed as mean \pm standard deviation.

$\mathrm{BP}=$ blood pressure; $\mathrm{BWi}=$ Body weight-indexed $\mathrm{HR}=$ heart rate; $\mathrm{RER}=$ respiratory exchange ratio $\mathrm{RPP}=$ rate pressure product; $\mathrm{VE} / \mathrm{VCO} 2$ slope $=$ regression slope relating minute ventilation to carbon dioxide output; $\mathrm{VO2}=$ oxygen uptake.

$* p<0.05$ vs patients with peak VO2 $>14$ 
Table 3

Univariate and multivariate predictors of peak $\mathrm{VO} 2$.

\begin{tabular}{lclcc}
\hline Variable & $\begin{array}{l}\text { Univariate } \\
\text { beta coefficient }\end{array}$ & $P$ value & $\begin{array}{l}\text { Multivariate } \\
\text { beta coefficient }\end{array}$ & $P$ value \\
\hline Age & 0.51 & 0.0001 & -0.407 & 0.0001 \\
Sex & & 0.0001 & 0.327 & 0.0001 \\
BMI & NS & & NS \\
ECrCl & 0.32 & 0.0001 & & NS \\
Haemoglobin & 0.38 & 0.0001 & & NS \\
EF & 0.26 & 0.0001 & & \\
fT3 & 0.24 & 0.0001 & & NS \\
PRA & & NS & & 0.0001 \\
Aldosterone & & NS & & \\
Norepinephrine & -0.301 & 0.0001 & & 0.267 \\
BNP & -0.48 & 0.0001 & -0.267 & \\
\hline
\end{tabular}

BMI: body mass index; $\mathrm{ECrCl}$ : estimated creatinine clearance by Cockroft-Gault formula; EF: ejection fraction; fT3: free triiodothyronine; PRA: plasma renin activity; BNP: brain natriuretic peptide. All variables found to be statistically significant at univariate linear regression $(P<0.05)$ were included into the multiple linear regression model.

In the overall population, peak VO2 was positively correlated (all $p<0.001)$ with EF $(r=0.26)$, fT3 $(r=0.24)$, ECrCl $(r=0.32)$, haemoglobin $(r=0.38)$, and inversely correlated with age $(r=-0.51)$, BNP $(r=-0.48)$ and norepinephrine level $(r=-0.301)$. At multivariate analysis only age, gender, BNP level (all $p<0.0001$ ) were independently associated with peak VO2 (Table 3$)\left(R^{2} 0.54\right.$ for the total model).

Patients were then stratified according to functional capacity. In the 84 patients with peak VO2 $>14 \mathrm{ml} / \mathrm{min} / \mathrm{kg}$, peak VO2 showed a positive relation with $\mathrm{EF}(r=0.265, p=0.015)$, and a negative relation with age $(r=-0.422, p<0.001)$, BNP $(r=-0.255, p=0.019)$ and norepinephrine level $(r=-0.310, p=0.005)$. At multivariate analysis only age $(p<0.001)$, gender $(p=0.015)$, and $\mathrm{EF}(p=0.027)$ were independently related to peak VO2 (Table 4$)\left(R^{2} 0.32\right.$ for the total model). On the other hand, in the 156 patients with peak $\mathrm{VO} 2<14 \mathrm{ml} / \mathrm{min} / \mathrm{kg}$, peak VO2 correlated with estimated $\mathrm{ECrCl}(r=0.273, p=0.001)$, haemoglobin $(r=0.244, p=0.005)$, fT3 $(r=0.313, p<0.001)$ and inversely with age $(r=-0.267, p<0.001)$, BNP $(r=-0.209, p=0.011)$ (Fig. 1$)$.

At multivariate analysis only gender $(p<0.0001)$, fT3 $(p=0.003)$, and BNP level $(p=0.046)$ were independently related to peak VO2 (Table 4) ( $R^{2} 0.25$ for the total model).

3.1. Exercise capacity according to the presence of low T3 syndrome in patients with severely compromised functional capacity (i.e. patients with peak $\mathrm{VO} 2<14 \mathrm{ml} / \mathrm{min} / \mathrm{kg}$ )

Forty-six patients (30\%) of the group of patients with peak $\mathrm{VO} 2<14 \mathrm{ml} / \mathrm{min} / \mathrm{kg}$ had a low T3' status, i.e. fT3 below the lower limit of the reference interval (i.e. $<2.1 \mathrm{ng} / \mathrm{L}$ ) associated with normal level of TSH and fT4. No difference was found between the two groups of patients with low T3 and normal thyroid profile with regard to age $(67.4 \pm 12$ vs $65.2 \pm 9.5)$, gender (69.6\% males vs $73.4 \%)$, NYHA class (2.6 \pm 0.7 vs $2.4 \pm 0.6)$, BMI $\left(26.4 \pm 4.3 \mathrm{~kg} / \mathrm{m}^{2}\right.$ vs $\left.27.3 \pm 4.8 \mathrm{~kg} / \mathrm{m}^{2}\right)$, EF $(30.37 \% \pm 8.6$ vs $30.65 \% \pm 8.4)$, levels of BNP [250 (112-676) ng/L vs 214 (226-477) ng/L], aldosterone [150 (79222) ng/L vs 142 (92-226) ng/L], PRA [1.58 (0.3-6.1) ng/L/h vs 1.69 $(0.4-5.1) \mathrm{ng} / \mathrm{L} / \mathrm{h}$ ] and norepinephrine [602 (450-816) ng/L vs 582 (364-802) ng/L]. As compared to patients with normal hormonal pattern, those with low fT3 serum levels had lower ECrCl $(64 \pm 34 \mathrm{ml} / \mathrm{min}$ vs $81 \pm 33 \mathrm{ml} / \mathrm{min}, p=0.005)$ and haemoglobin $(13.1 \pm 1.6 \mathrm{~g} / \mathrm{dl}$ vs $13.9 \pm$ $1.4 \mathrm{~g} / \mathrm{dl}, p=0.004)$.

As far as exercise capacity is concerned, patients with low T3 syndrome reached a lower workload ( $54 \pm 20 \mathrm{~W}$ vs $67 \pm 20 \mathrm{~W} p<0.001)$, even if corrected for body weight $(0.76 \pm 0.26 \mathrm{~W} / \mathrm{kg}$ vs $0.87 \pm 0.23 \mathrm{~W} / \mathrm{kg}$ vs $p=0.012$ ), showed worse ventilatory efficiency expressed as a higher VE/VCO2 slope ( $43 \pm 10$ vs $39 \pm 9, p=0.027$ ) and reduced exercise capacity as expressed by peak VO2 $(9.0 \pm 2 \mathrm{ml} / \mathrm{min} / \mathrm{kg}$ vs $10.2 \pm 2 \mathrm{ml} /$ $\mathrm{min} / \mathrm{kg} p=0.012$ ). There were no differences in basal oxygen consumption $(0.18 \pm 0.7 \mathrm{ml} / \mathrm{min} / \mathrm{kg}$ vs $0.18 \pm 0.08 \mathrm{ml} / \mathrm{min} / \mathrm{kg})$, circulatory power $(1424 \pm 572 \mathrm{mmHg} \mathrm{ml} / \mathrm{min} / \mathrm{kg}$ vs $1543 \pm 453 \mathrm{mmHg} \mathrm{ml} / \mathrm{min} / \mathrm{kg})$, oxygen pulse at peak exercise $(6.2 \pm 2.3 \mathrm{~mL} /$ beat vs $7.0 \pm 2.2 \mathrm{~mL} /$ beat, $p=0.068)$, peak heart rate $(108 \pm 25 \mathrm{bpm}$ vs $115.7 \pm 25 \mathrm{bpm})$.

\subsection{Diagnostic accuracy of fT3 and BNP assays in identifying reduced} functional capacity among patients complaining symptoms

At multivariate analysis in symptomatic patients (i.e. NYHA classes II-III, $n=203$ ), fT3 and BNP were independently related to peak VO2 $(P=0.003)$, together with age and gender. ROC curve analysis indicated the ability of BNP and fT3 to identify patients with reduced functional capacity, i.e. peak $\mathrm{VO} 2<14 \mathrm{ml} / \mathrm{min} / \mathrm{kg}$, (BNP: optimum cutpoint $264 \mathrm{ng} / \mathrm{L}$, sensitivity 50\%, specificity $89 \%$, AUC $0.707,95 \% \mathrm{CI}$ 0.674-0.799; fT3: optimum cut-point $2.1 \mathrm{ng} / \mathrm{L}$, sensitivity $36 \%$, specificity of $93 \%$, AUC $0.660,95 \%$ CI $0.590-0.725$, respectively; both BNP and fT3: AUC $0.770,95 \%$ CI 0.706-0.827). The percentage of patients with peak $\mathrm{VO} 2<14 \mathrm{ml} / \mathrm{min} / \mathrm{kg}$ was highest among those with both low fT3 and BNP above the cut-off value, as shown in Fig. 2.

\section{Discussion}

This study confirms the association of neurohormonal activation and exercise intolerance, as expressed by peak VO2, particularly in those with peak $\mathrm{VO} 2<14 \mathrm{ml} / \mathrm{min} / \mathrm{kg}$. Furthermore, in this subset of patients, among all neurohormones examined, fT3 resulted independently related to peak VO2, together with BNP.

Table 4

Univariate and multivariate predictors of peak VO2 in patients with peak VO2 $>$ or $<14 \mathrm{ml} / \mathrm{min} / \mathrm{kg}$.

\begin{tabular}{|c|c|c|c|c|c|c|c|c|}
\hline & \multicolumn{4}{|c|}{ Peak VO2 $>14(n=84)$} & \multicolumn{4}{|c|}{ Peak VO2<14 $(n=156)$} \\
\hline & $\begin{array}{l}\text { Univariate, } \\
\text { beta coefficient }\end{array}$ & $P$ & $\begin{array}{l}\text { Multivariate, } \\
\text { beta coefficient }\end{array}$ & $P$ & $\begin{array}{l}\text { Univariate, } \\
\text { beta coefficient }\end{array}$ & $P$ & $\begin{array}{l}\text { Multivariate, } \\
\text { beta coefficient }\end{array}$ & $P$ \\
\hline Age, years & -0.422 & 0.0001 & -0.405 & 0.0001 & -0.267 & 0.001 & & NS \\
\hline Sex & & 0.0001 & -0.244 & 0.015 & & 0.011 & -0.304 & 0.0001 \\
\hline Creatinine & & NS & & & & NS & & \\
\hline $\mathrm{ECrCl}:$ & & NS & & & 0.273 & 0.001 & & NS \\
\hline Haemoglobin & & NS & & & 0.244 & 0.005 & & NS \\
\hline \multicolumn{9}{|l|}{ PRA } \\
\hline Aldosterone & & NS & & & & & & \\
\hline Norepinephrine & -0.310 & 0.005 & & NS & & & & \\
\hline LVEF & 0.265 & 0.015 & 0.262 & 0.027 & & NS & & \\
\hline fT3 & & NS & & & 0.313 & 0.001 & 0.252 & 0.003 \\
\hline BNP & -0.255 & 0.019 & & NS & 0.209 & 0.011 & -0.181 & 0.046 \\
\hline
\end{tabular}

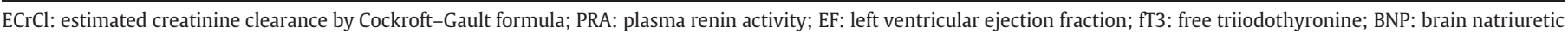
peptide. All variables found to be statistically significant at univariate linear regression $(P<0.05)$ were included into the multiple linear regression model. 

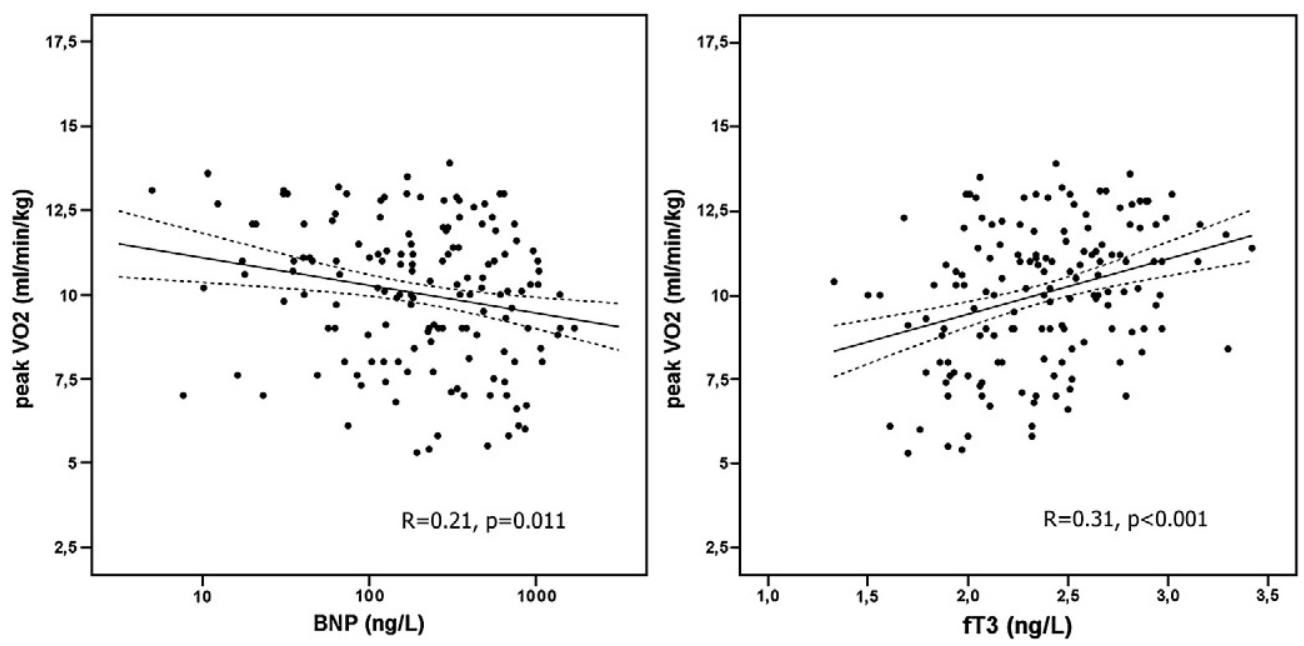

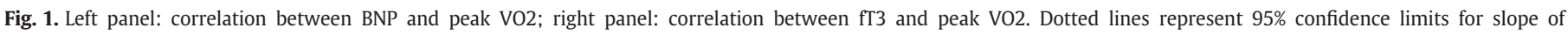
regression line.

These findings support the hypothesis that exercise capacity limitation in patients with severe functional impairment may have a multifactorial origin: in particular, besides a decreased cardiac output reserve, abnormal peripheral mechanisms, influenced by the neuro-hormonal regulatory system, may play a crucial role. It is important to highlight that among all indices of the neurohormonal axes studied (including the adrenergic and renin-angiotensinaldosterone systems), BNP and biologically active thyroid hormone T3 resulted independently related to functional capacity in this subset of patients. This data confirms the close relationship between exercise tolerance and B-type natriuretic peptide levels previously shown in HF patients [26-28], but also indicate the existence of an association between thyroid function and exercise capacity, whose pathophysiologic meaning needs to be investigated.

The mechanisms correlating BNP production and biological active thyroid hormone expression with peak VO2 are likely different. Ventricular cardiomyocyte stretching, ventricular fibrosis, hypoxia, and neurohormonal system activation are considered as main stimuli for B-type natriuretic hormone production and secretion $[23,29]$. Therefore, the measurement of circulating BNP and its relatedpeptides is now considered to be a useful clinical marker of myocardial function and neuro-hormonal activation [30-32]. The association between BNP and peak VO2 confirms the relevance of haemodynamic conditions $[23,29,33]$ and overall neurohormonal activation [24] in determining exercise capacity.

On the other hand, low T3 status is a frequent marker of systemic involvement in HF characterized by multi-organ impairment [34] and is associated with reduced peripheral conversion of the T4 prohormone into the biological active form T3. As concerns $\mathrm{HF}$, the relation between low fT3 and reduced functional capacity could be explained by thyroid hormonal influence at both cardiovascular and peripheral level through different pathways: a) direct T3 effect on trophism and function of cardiomyocytes, with a positive chronotropic and inotropic effect [35]; b) modulatory action on sympathetic outflow (15-16); c) T3 vessel-relaxing action on peripheral vasculature; d) the effect on metabolism and function of skeletal muscles [18]. These last two points warrant specific attention, owing to the greater role of abnormal peripheral mechanisms, i.e. skeletal muscle with impaired oxidative metabolism and increased lactate production as documented in mild hypothyroidism [18] and decreased muscle vasodilation, in determining exercise intolerance in moderate and severe chronic HF [36]. However, despite a trend (though not significant) toward a lower oxygen pulse at peak exercise (stroke volume at peak exercise times the artero-venous difference) in patients with low T3 syndrome and peak VO2 below $14 \mathrm{ml} / \mathrm{min} / \mathrm{kg}$, no other differences in parameters evaluating central hemodynamic, such as the circulatory power, a surrogate of the cardiac power (i.e. the product of cardiac output and central aortic pressure) and the heart rate, were found. Therefore, the present data do not allow to draw straightforward conclusions about the greater role of peripheral factors vs central haemodynamics in reducing exercise capacity and further studies specifically focused on this issue are needed.

These results are in accordance with the independent, additive prognostic value of BNP and fT3 in HF [37] and suggest the interesting potential role of synthetic L-T3 replacement as a novel therapeutic approach to improve exercise capacity in HF patients [38].

Finally, the correlation shown among BNP, fT3 and peak VO2 and in particular the ability of the combination of high BNP and low normal $\mathrm{T} 3$ in identifying patients with peak $\mathrm{VO} 2<14 \mathrm{ml} / \mathrm{min} / \mathrm{kg}$ confirms the ability of their combined assay to improve the power of risk stratification.

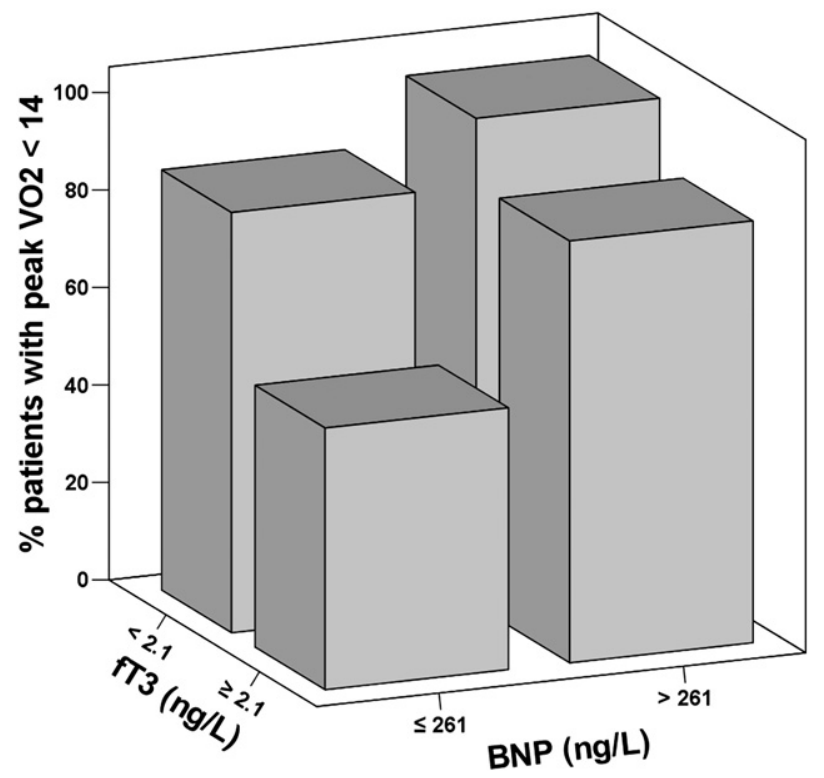

Fig. 2. Percentages of patients in NYHA class II/III with peak $\mathrm{VO} 2<14 \mathrm{ml} / \mathrm{min} / \mathrm{kg}$, according to fT3 and BNP cut-points, by Receiver Operating Characteristic analysis (low fT3/high BNP: 97\%; low fT3/low BNP: 87\%; high fT3/high BNP: 79\%; high fT3/low BNP: $54 \%)$. 
Our study has several limitations. Emphasis on the described association does not prove causality: the hypothesis as to whether changes in thyroid hormone metabolism could contribute mechanistically to impaired functional capacity still needs to be fully determined. To avoid possible confounders, we did select patients according to thyroid function, to medications directly affecting thyroid function, and to presence of systemic comorbidities known to promote a low T3 syndrome and a reduced functional capacity, independently of cardiac function. For these reasons, the findings of the present study cannot be generalized to unselected populations with HF.

In conclusion, low fT3 status is independently associated with functional capacity in severe HF. Both BNP and thyroid hormone level are related to exercise capacity in severely compromised $\mathrm{HF}$ patients.

\section{Acknowledgment}

The authors of this manuscript have certified that they comply with the Principles of Ethical Publishing in the International Journal of Cardiology [39].

\section{References}

[1] Clark AL, Poole-Wilson PA, Coats AJS. Exercise limitation in chronic heart failure: central role of the periphery. J Am Coll Cardiol 1996;28:1092-102.

[2] Cohn JN, Johnson GR, Shabetai R, et al. Ejection fraction, peak exercise oxygen consumption, cardiothoracic ratio, ventricular arrhythmias, and plasma norepinephrine as determinants of prognosis in heart failure. The V-HeFT VA Cooperative Studies Group. Circulation 1993;87:VI5-VI16.

[3] O'Neill JO, Young JB, Pothier CE, Lauer MS. Peak oxygen consumption as a predictor of death in patients with heart failure receiving beta-blockers. Circulation 2005;111:2313-8.

[4] Harringhton D, Coats A. Mechanisms of exercise intolerance in congestive heart failure. Curr Opin Cardiol 1997;12:224-32.

[5] Packer M. The neuro-hormonal hypothesis: a theory to explain the mechanisms of disease progression in heart failure. J Am Coll Cardiol 1992;20:248-54.

[6] Cohen-Solal A, Logeart D, Guiti C, Dahan M, Gourgon R. Cardiac and peripheral responses to exercise in patients with chronic heart failure. Eur Heart J 1999;20: 931-45.

[7] Manowitz NR, Mayor GH, Klepper MJ, DeGroot LJ. Hypothyroidism and thyroid sick syndrome in patients with moderate to severe congestive heart failure. Am J Ther 1996;3:797-801.

[8] Hamilton MA, Stevenson LW, Luu M, Walden JA. Altered thyroid hormone metabolism in advanced heart failure. J Am Coll Cardiol 1990:16:91-5.

[9] Pingitore A, Landi P, Taddei MC, Ripoli A, L'Abbate A, Iervasi G. Triiodothyronine levels for risk stratification of patients with chronic heart failure. Am J Med 2005;118:132-6.

[10] Kozdag G, Ural D, Vural A, et al. Relation between free triiodothyronine/free thyroxine ratio, echocardiographic parameters and mortality in dilated cardiomyopathy. Eur J Heart Fail 2005;7:113-8.

[11] Ascheim DD, Hryniewicz K. Thyroid hormone metabolism in patients with congestive heart failure: the low triiodothyronine state. Thyroid 2002;12:511-5.

[12] Iervasi G, Pingitore A, Landi P, et al. Low T3 syndrome: a strong prognostic predictor of death in patients with heart disease. Circulation 2003:107:708-13.

[13] Shanoudy H, Soliman A, Moe S, et al. Early manifestations of "sick euthyroid" syndrome in patients with compensated chronic heart failure. J Card Fail 2001;7: 146-52.

[14] Utiger DR. Low serum triiodothyronine concentration predict mortality in patients with heart failure (Commentary). Clin Thyroid 2005;17:16.

[15] Klein I, Ojamaa K. Thyroid hormone and the cardiovascular system. N Engl J Med 2001:344:501-9.

[16] Kahaly GJ, Dillmann WH. Thyroid hormone action in the heart. Endocr Rev 2005;6: 704-28.
[17] Sabatino L, Colantuoni A, Iervasi G. Is the vascular system a main target for thyroid hormones? From molecular and biochemical findings to clinical perspectives. Curr Vasc Pharmacol 2005;3:133-45.

[18] Monzani F, Caraccio N, Siciliano G, Manca L, Murri L, Ferranini E. Clinical and biochemical features of muscle dysfunction in subclinical hypotiroidism. J Clin Endocrinol Metab 1997;82:3315-8.

[19] Pantos C, Dritsas A, Mourouzis I, et al. Thyroid hormone is a critical determinant of myocardial performance in patients with heart failure: potential therapeutic implications. Eur J Endocrinol 2007;157:515-20.

[20] Roberts CG, Ladenson PW. Hypothyroidism. Lancet 2004;363:793-803.

[21] Cooper DS. Hyperthyroidism. Lancet 2003;362:459-68.

[22] Schiller NB, Shah PM, Crawford M, et al. Recommendations for quantitation of the left ventricle by two-dimensional echocardiography. American Society of Echocardiography Committee on Standards, Subcommittee on Quantitation of Two-Dimensional Echocardiograms. J Am Soc Echocardiogr 1989;2:358-67.

[23] Emdin M, Passino C, Prontera C, et al. Cardiac natriuretic hormones, neurohormones, thyroid hormones and cytokines in normal subjects and patients with heart failure. Clin Chem Lab Med 2004;42:627-36.

[24] Prontera C, Emdin M, Zucchelli GC, Ripoli A, Passino C, Clerico A. Natriuretic peptides (NPs): automated electrochemiluminescent immunoassay for N-terminal pro-BNP compared with IRMAs for ANP and BNP in heart failure patients and healthy individuals. Clin Chem 2003:49:1552-4.

[25] Mancini DM, Eisen H, Kussmaul W, Mull R, Edmunds LH, Wilson JR. Value of peak exercise consumption for optimal timing of cardiac transplantation in ambulatory patients with heart failure. Circulation 1991;83:778-86.

[26] Kruger S, Graf J, Kunz D, Stickel T, Hanrath P, Janssens U. Brain natriuretic peptide levels predict functional capacity in patients with chronic heart failure. J Am Coll Cardiol 2002;40:718-22.

[27] Williams SG, Ng LL, O'Brien RJ, Taylor S, Li YF, Tan LB. Comparison of plasma Nbrain natriuretic peptide, peak oxygen consumption, and left ventricular ejection fraction for severity of chronic heart failure. Am J Cardiol 2004;93:1560-1.

[28] Passino C, Poletti R, Bramanti F, Prontera C, Clerico A, Emdin M. Neuro-hormonal activation predicts ventilatory response to exercise and functional capacity in patients with heart failure. Eur J Heart Fail 2006;8:46-53.

[29] Hunt SA. American College of Cardiology; American Heart Association Task Force on Practice Guidelines (Writing Committee to Update the 2001 Guidelines for the Evaluation and Management of Heart Failure). ACC/AHA 2005 guideline update for the diagnosis and management of chronic heart failure in the adult: a report of the American College of Cardiology/American Heart Association Task Force on Practice Guidelines (Writing Committee to Update the 2001 Guidelines for the Evaluation and Management of Heart Failure). J Am Coll Cardiol 2005;46:e1-e82.

[30] Doust JA, Glasziou PP, Pietrzak E, Dobson AJ. A systematic review of the diagnostic accuracy of natriuretic peptides for heart failure. Arch Intern Med 2004;164: 1978-84.

[31] Ewald B, Ewald D, Thakkinstian A, Attia J. Meta-analysis of B type natriuretic peptide and $\mathrm{N}$-terminal pro $\mathrm{B}$ natriuretic peptide in the diagnosis of clinical heart failure and population screening for left ventricular systolic dysfunction. Intern Med J 2008;38:101-13.

[32] Tang WH, Francis GS, Morrow DA, et al. Biochemistry Laboratory Medicine. National Academy of Clinical Biochemistry Laboratory Medicine practice guidelines: clinical utilization of cardiac biomarker testing in heart failure. Circulation 2007; 116:e99-e109.

[33] Clerico A. Recchia FA, Passino C, Emdin M. Cardiac endocrine function is an essential component of the homeostatic regulation network: physiological and clinical implications. Am J Physiol Heart Circ Physiol 2006;290:H17-29.

[34] Maldonado LS, Murata GH, Hershman JM, Braunstein GD. Do thyroid function tests independently predict survival in the critically ill? Thyroid 1992;2:119-23.

[35] Klein I, Danzi S. Thyroid disease and the heart. Circulation 2007;116:1725-35.

[36] Working Group on Cardiac Rehabilitation \& Exercise Physiology and Working Group on Heart Failure of the European Society of Cardiology. Recommendations for exercise testing in chronic heart failure patients. Eur Heart J 2001;22:37-45.

[37] Passino C, Pingitore A, Patrizia L, et al. Prognostic value of combined measurement of brain natriuretic peptide and triiodothyronine in heart failure. J Card Fail 2009; 15:35-40.

[38] Pingitore A, Galli E, Barison A, et al. Acute effects of triiodothyronine (T3) replacement therapy in patients with chronic heart failure and low-T3 syndrome: a randomized, placebo-controlled study. J Clin Endocrinol Metab 2008;93:1351-8.

[39] Coats AJ. Ethical authorship and publishing. Int J Cardiol 2009;131:149-50. 